\title{
Manifestaciones cutáneas de amiloidosis sistémica como clave diagnóstica. Caso clínico
}

\author{
FÉLIX FICH S. ${ }^{1}$, MARCO CHAHUÁN Y. ${ }^{2}$, Mª MAGDALENA FARÍAS N. ${ }^{3}$, \\ CONSUELO CÁRDENAS D. ${ }^{1}$, ÁLVARO ABARZÚA A. ${ }^{1}$, \\ GABRIELA ARAYA C. ${ }^{1}$, SERGIO GONZÁLEZ B. ${ }^{4}$
}

\section{AA amyloidosis with cutaneous manifestations. Report of one case}

Systemic amyloidosis is a rare disease that can affect any organ. Its clinical manifestations are varied and nonspecific. The skin involvement of this disease is common and can be easily recognized on physical examination. We report a 57-year-old male presenting with a two years history of malaise, dyspnea and myalgias. On physical examination, ungueal dystrophy, orange pigmentation of eyelids with periocular petechiae and mild macroglossia were observed. Incisional biopsies of the eyelids, cheeks and hands were obtained. The pathological study demonstrated amyloid deposits. Since protein electrophoresis was normal, the diagnosis of AA amyloidosis was postulated.

(Rev Med Chile 2012; 140: 499-502).

Key words: Amyloid; Amyloidosis; Skin diseases.

L a amiloidosis es a una enfermedad poco frecuente caracterizada por el depósito extra$\checkmark$ celular anormal de amiloide, una sustancia proteica fibrilar e insoluble con estructura beta plegada. El tipo de amiloide que se deposita varía según el tipo de amiloidosis. Los más comunes son: los fragmentos de cadenas livianas kappa o lambda de inmunoglobulinas en la amiloidosis sistémica primaria $(\mathrm{AL})$; los fragmentos de proteína amiloide sérica A en la amiloidosis sistémica secundaria asociada con trastornos inflamatorios crónicos (AA); y la $\beta 2$-microglobulina en la amiloidosis asociada a diálisis ${ }^{1}$.

En la amiloidosis sistémica adquirida, el depósito de amiloide puede afectar cualquier órgano, incluyendo corazón, riñones, tracto gastrointestinal, sistema músculo-esquelético, sistema nervioso y piel. El tejido afectado pierde su estructura normal, lo que genera una disfunción a medida que avanza la enfermedad y aumenta el depósito de amiloide. El diagnóstico definitivo se confirma

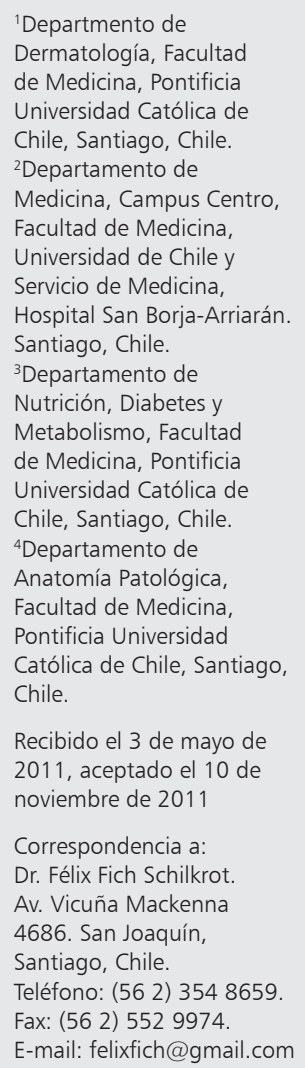

con la demostración del depósito de sustancia amiloide en el órgano afectado, mediante el estudio histológico con tinción específica de rojo Congo ${ }^{2}$.

$\mathrm{La}$ amiloidosis muchas veces es poco considerada al momento de plantear hipótesis diagnósticas frente a un paciente, ya que es una enfermedad infrecuente y cuyas manifestaciones clínicas son variadas e inespecíficas. De hecho, en un análisis retrospectivo de 11 pacientes chilenos con diagnóstico de amiloidosis sistémica hubo dos casos en que el diagnóstico se realizó en el estudio post mortem ${ }^{3}$.

En este contexto, creemos que las manifestaciones semiológicas cutáneas son de gran valor para sospechar la enfermedad, como en el caso que presentaremos a continuación.

\section{Caso clínico}

Paciente de 57 años, sexo masculino, conserje, con antecedente de tabaquismo activo. Presentaba historia de múltiples hospitalizaciones en distintos 
centros durante el año 2010 para estudio de hemoptisis autolimitada y de escasa cuantía en relación a esfuerzo físico. Al preguntar dirigidamente, refería historia de 2 años de astenia, adinamia, disnea leve en relación a esfuerzos que a través de los años fue empeorando apareciendo ortopnea y disnea ante pequeños esfuerzos, mialgias en piernas y rigidez matinal de articulaciones de manos de 10-15 minutos de duración, sin artralgias.

Presentaba radiografía de tórax, ecografía abdominal, endoscopía digestiva alta, ecocardiograma, perfil bioquímico, creatinina plasmática, pruebas hepáticas y de coagulación normales. Tuvo un hemograma con leve anemia (hematocrito $35 \%)$ y VHS elevada. En controles posteriores persistió con anemia normocítica-normocrómica de carácter leve, pero VHS se normalizó.

Presentó una tomografía axial computarizada (TAC) de tórax, 3 días post hemoptisis, que mostró

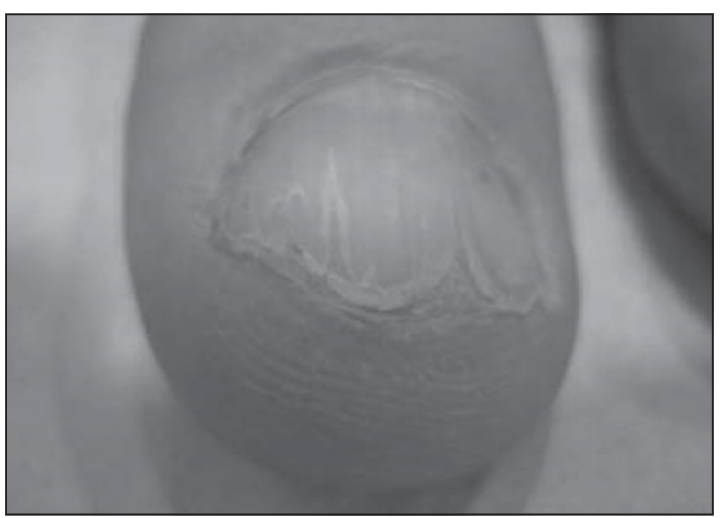

Figura 1. Distrofia ungueal: onicólisis, fragilidad ungueal y estrías longitudinales.

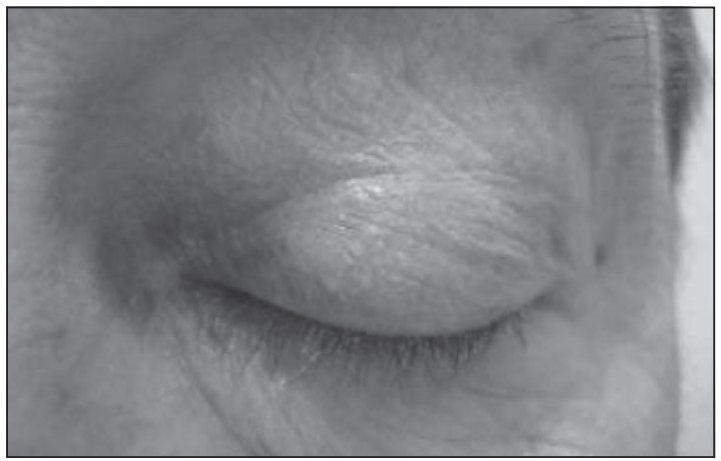

Figura 3. Petequias y pigmentación anaranjada, periocular. múltiples imágenes de "vidrio esmerilado" difusas sugerentes de hemorragia alveolar y enfisema pulmonar, pero en TAC de control mostró sólo enfisema leve. Se realizó fibrobroncoscopía que resultó normal, sin alteraciones en lavado bronco alveolar. Presentaba exámenes inmuno-reumatológicos negativos (ANA, AntiDNAds, ANCA por IFI, Coombs directo e indirecto, FR). Radiografía de manos mostraba leves cambios degenerativos en articulaciones interfalángicas distales. Al examen físico, se pesquisó distrofia ungueal (Figura 1), aumento de volumen de partes blandas de manos sin edema (Figura 2), pigmentación anaranjada de párpados con petequias perioculares (Figura 3) y leve macroglosia (Figura 4). Por estos hallazgos se sugirió descartar enfermedad de depósito, postulando como hipótesis diagnóstica amiloidosis sistémica. Se realizó biopsia incisional de párpado, mejilla y mano, que mostró un infiltrado amorfo

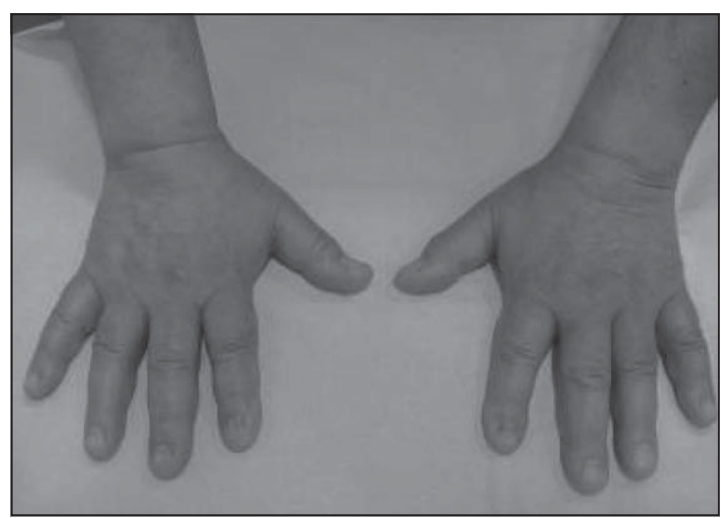

Figura 2. Aumento de volumen de partes blandas de manos.

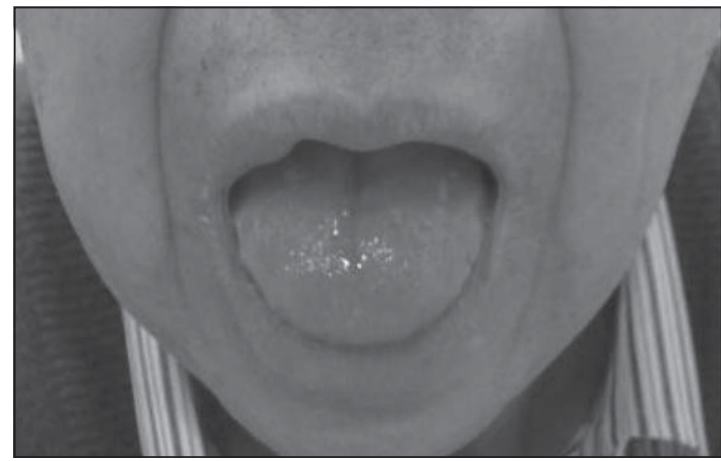

Figura 4. Macroglosia. 


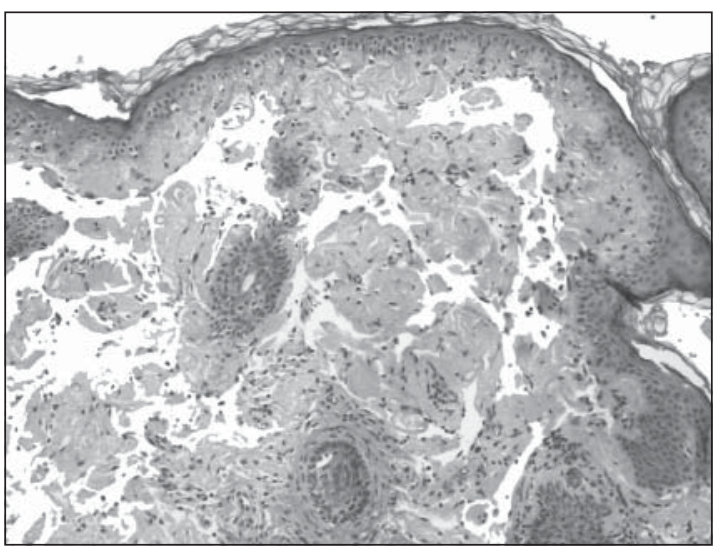

Figura 5. Depósitos amiloideos amorfos, intersticiales, hialinos, eosinofílicos. HE, 100x.

intersticial de material hialino eosinofílico de tipo amiloideo, además de focos de microhemorragia (Figura 5 y 6). Las tinciones de Cresil violeta y rojo Congo fueron positivas con dicroísmo verde manzana positivo bajo luz polarizada y resistencia a permanganato de potasio.

Se realizó ecocardiograma que mostró hipertrofia de ventrículo izquierdo, compatible con depósito amiloideo. Con estudio de tiroides y electroforesis de proteínas normales, se planteó el diagnóstico de una amiloidosis AA.

\section{Discusión}

La amiloidosis AA es un trastorno caracterizado por el depósito extracelular de fibrillas compuestas por fragmentos de proteína amiloide sérica $A$, un reactante de fase aguda. Puede ser secundaria a un gran número de enfermedades inflamatorias crónicas (enfermedades reumatológicas, enfermedad inflamatoria intestinal, etc.), infecciones crónicas y neoplasias ${ }^{1-3}$.

El depósito de amiloide en la piel y tejido subcutáneo se ha descrito en $40 \%$ de las amiloidosis sistémicas ${ }^{4}$, siendo más frecuente de encontrar en amiloidosis AL que en AA. El hallazgo más frecuente son lesiones purpúricas como petequias y equímosis, reportado en 5 a 16\% del total de las amiloidosis sistémicas ${ }^{5,6}$. El púrpura se puede manifestar de manera espontánea o bien luego de un trauma, el cual refleja la infiltración de amiloide en la pared de los capilares sanguíneos. Los sitios

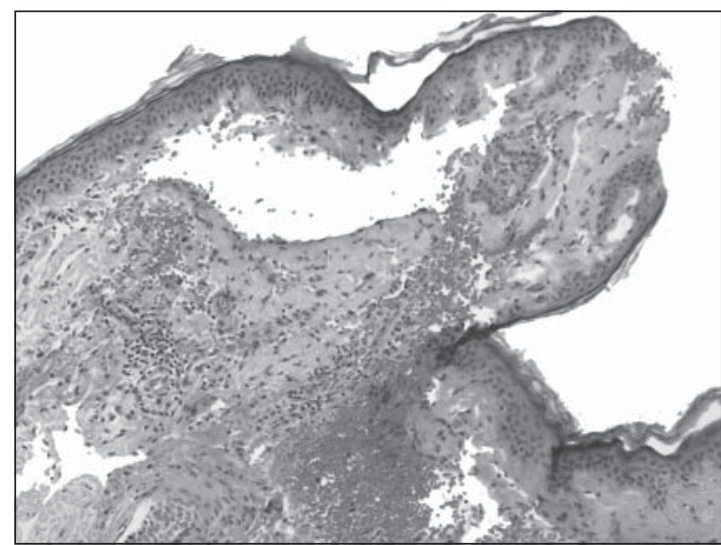

Figura 6. Depósitos de amiloide y telangiectasias superficiales con focos de hemorragia. HE, 100x.

más frecuentes en que se desarrollan las lesiones purpúricas son la zona superior del tronco, cuello y rostro, especialmente la zona periocular. Otras lesiones frecuentes corresponden a nódulos o pápulas de consistencia gomosa, las cuales reflejan el compromiso dérmico. En la lengua, la infiltración difusa puede generar macroglosia en $20 \%$ de los casos ${ }^{7}$. El compromiso ungueal es infrecuente y se puede manifestar como fragilidad, onicólisis, engrosamiento subungueal, estrías y anoniquia ${ }^{8}$. En pocos casos, la infiltración difusa de la piel puede generar engrosamiento de ésta y manifestarse como un cuadro similar a la esclerodermia?.

El diagnóstico de amiloidosis requiere la demostración histológica del depósito de tejido amiloide en el tejido afectado. Con la tinción de hematoxilina-eosina la sustancia amiloide se presenta como un material amorfo eosinofílico, cuya identificación puede ser difícil. Por esto, se utilizan tinciones especiales como el rojo Congo con lo que se produce una birrefringencia verde manzana, lo cual confirma el diagnóstico ${ }^{1}$. Dado que el riñón, corazón e hígado son los órganos más afectados por esta enfermedad, la biopsia en cualquiera de estos órganos es positiva en $90 \%$ de los casos $^{3}$. Sin embargo, es un procedimiento riesgoso y puede comprometer la vida del paciente. Mientras que la biopsia hepática puede producir hemorragia e incluso ruptura ${ }^{6}$, la biopsia cardíaca puede generar complicaciones tales como neumotórax, tamponamiento cardíaco o arritmias ${ }^{10}$. Por esta razón, se han publicado métodos menos invasivos, aunque 
con menor sensibilidad, tales como la punción aspirativa de grasa abdominal, biopsia rectal y la biopsia de médula ósea, con sensibilidad del orden de $60-80 \%, 50-70 \%$, y $50-55 \%$, respectivamente ${ }^{3}$. La biopsia cutánea podría plantearse como una herramienta diagnóstica de amiloidosis sistémica, reportándose en la literatura que hasta 97\% de las muestras cutáneas de pacientes con amiloidosis sistémica presentan hallazgos histológicos positivos para amiloide, considerando incluso aquellas muestras histológicas de piel completamente sana9. Los hallazgos histológicos de las lesiones cutáneas son característicos en cuadros de amiloidosis sistémicas, lo que permite descartar una amiloidosis cutánea primaria. En las lesiones cutáneas de amiloidosis sistémica se observa indemnidad en la epidermis en la gran mayoría de los casos. Otras veces la epidermis se puede observar levemente atrófica debido a un depósito extenso de sustancia amiloide en la dermis papilar y reticular. La infiltración de tejido amiloide en vasos sanguíneos es frecuente, ya sea en plexos superficiales, profundos o subcutáneos. La distribución periférica de tejido amiloide en folículos pilosos, glándulas sebáceas y sudoríparas también es común. Otro hallazgo característico corresponde a anillos de amiloide alrededor de los adipocitos. En la amiloidosis cutánea primaria (liquenoide o macular), en cambio, el depósito de sustancia amiloide se limita sólo a las capas superficiales como dermis papilar y subpapilar9.

Presentamos este caso para demostrar la importancia de los signos cutáneos en el diagnóstico de la amiloidosis sistémica y plantear la biopsia cutánea como un procedimiento ambulatorio, fácil de realizar y casi sin riesgos, que puede contribuir de manera significativa en el diagnóstico temprano de esta enfermedad.

\section{Referencias}

1. Obici L, Perfetti V, Palladini G, Moratti R, Merlini G. Clinical aspects of systemic amyloid diseases. Biochim Biophys Acta 2005; 1753: 11-22.

2. Perfetto F, Moggi-Pignone A, Livi R, Tempestini A, Bergesio F, Matucci-Cerinic M. Systemic amyloidosis: a challenge for rheumatologist. Nat Rev Rheumatol 2010; 6: 417-29.

3. Palma CL, Grünholz D, Osorio G. Amiloidosis, comunicación de 11 casos y revisión de la literatura. Rev Med Chile 2005; 133: 655-61.

4. Touart DM, Sau P. Cutaneous deposition diseases. Part I. J Am Acad Dermatol 1998; 39: 149-71.

5. Gertz MA, Kyle RA. Primary systemic amiyloidosis: a diagnostic primer. Mayo Clin Proc 1989; 64: 1505-19.

6. Kyle R, Greipp P. Amyloidosis (AL). Clinical and laboratory features in 229 cases. Mayo Clin Proc 1983; 58: 665-83.

7. Steciuk A, Dompmartin A, Troussard X, Verneuil L, Macro M, Comoz F, et al. Cutaneous amyloidosis and possible association with systemic amyloidosis. Int $\mathrm{J}$ Dermatol 2002; 41: 127-32.

8. Prat C, Moreno A, Viñas M, Jucgla A. Nail dystrophy in primary systemic amyloidosis. J Eur Acad Dermatol 2008; 22: 107-9.

9. Lee DD, Huang CY, Wong CK. Dermatopathologic findings in 20 cases of systemic amiloidosis. Am J Dermatopathol 1998; 20: 438-42.

10. Fowles RE, Mason JW. Role of cardiac biopsy in the diagnosis and management of cardiac disease. Prog Cardiovasc Dis 1984; 27: 153-72. 